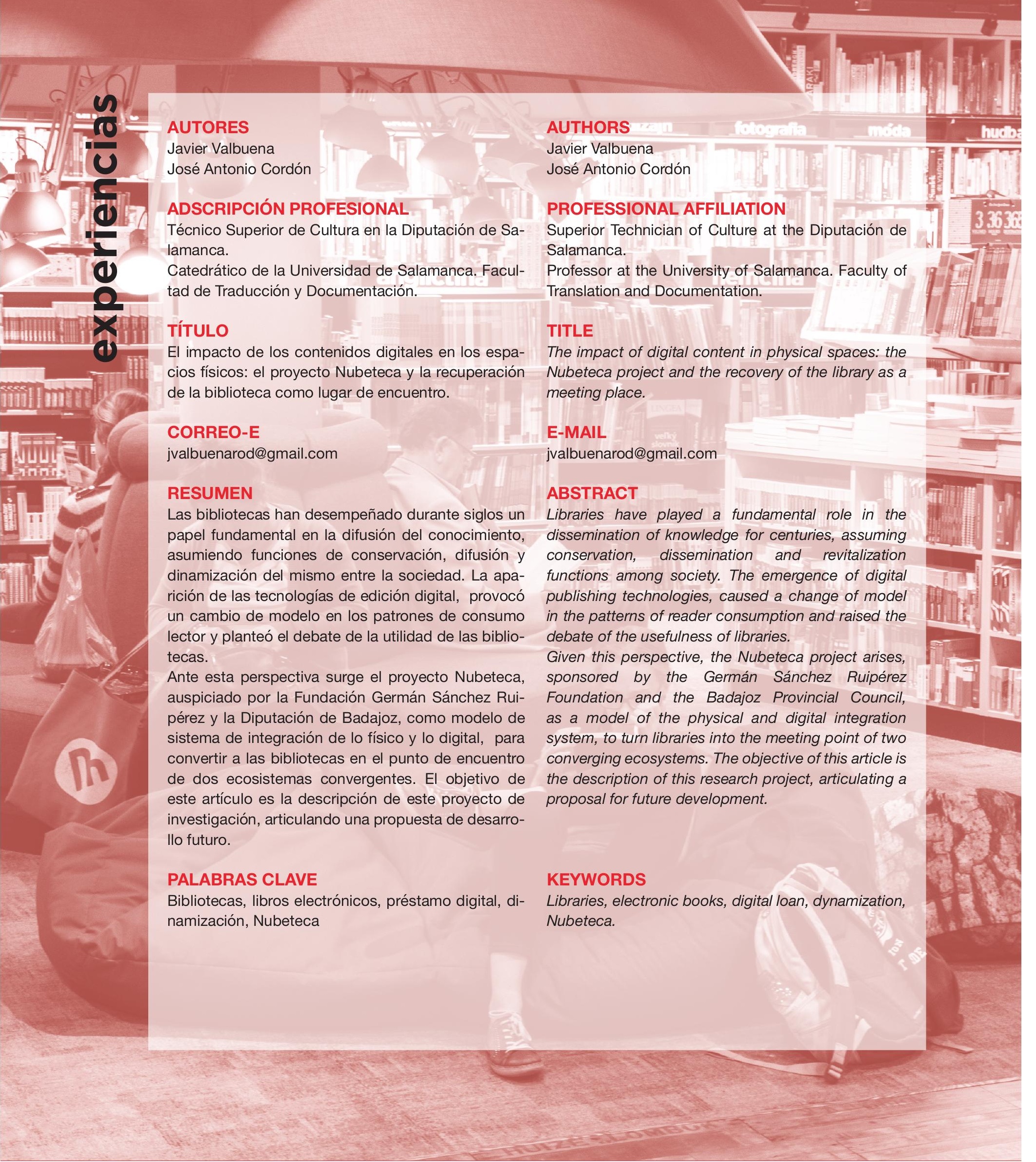




\section{El impacto de los contenidos digitales en los espacios físi- cos: el proyecto Nubeteca y la recuperación de la biblioteca como lugar de encuentro José Javier Valbuena}

\section{Introducción}

En un reciente artículo Muñoz Molina ponderaba las virtudes de lo real frente a los futuribles políticos, contrastando la solidez y seguridad de uno frente a la volatibilidad e inconsistencia de otros, constatándolo como

Visitar un centro de salud o una biblioteca o un laboratorio lo enfrenta a uno a la evidencia irrefutable de las cosas bien hechas, del mérito de quienes se entregan con solvencia y generosidad a trabajos muy dificiles y muy necesarios (MUÑOZ MOLINA, 2019).

Aunque más adelante se lamentaba de que en muchas ocasiones «los libros que consulto en la biblioteca están tan gastados por el uso que las páginas se me desencuadernan entre las manos». Esta imagen de la biblioteca como un centro emblemático, bastión de la cultura y enclave de referencia en ciudades, pueblos y barrios es fruto de siglos de existencia y de la esmerada labor de preservación y difusión del conocimiento que ha centrado sus actividades (DARNTON, 2010; MURRAY, 2014). Una imagen que durante siglos ha permanecido más o menos invariable, como han sido los objetos con los que trataba, dotados de una homogeneidad transparente en la medida en que la evolución de los formatos (libros, revistas, discos, películas, etc.) permanecía con una fidelidad inamovible vinculada al mundo de los átomos (NEGROPONTE, 1996). Sus funciones, sus modalidades de acceso y sus prestaciones han ido evolucionando con el tiempo, con una tendencia general hacia la apertura de sus espacios y colecciones, y con un movimiento centrífugo desde la conservación a la difusión, pero la fisicidad de su naturaleza no ha experimentado cambio alguno durante siglos. Leer un libro del siglo XVI, o visitar una biblioteca del siglo XVIII no nos produce más sorpresa que la puramente estética, pues las funcionalidades básicas asociadas al objeto y al edificio han permanecido invariables en el tiempo.

El gran cambio se produce a finales del siglo XX, y sobre todo en la primera década del siglo XXI, cuando la aparición y consolidación del libro electrónico introduce una transformación sustancial en el sistema de comunicación: la desmaterialización del conocimiento, la transformación de un movimiento en torno a los átomos a otro en torno a los bits, la preeminencia de los contenidos sobre los formatos, la posibilidad de que el conocimiento no dependa de su almacenamiento y gestión en los centros arbitrados para ello (las bibliotecas) sino que pueda circular libremente de una ma- 
La disminución del préstamo

de libros en las bibliotecas, la

falta de uso y de circulación

de estos es una constante

de los últimos diez años,

no solo en las bibliotecas

públicas, sino también

en las especializadas. La

Universidad de Yale, por

ejemplo, ha disminuido en un

$64 \%$ el número de préstamos
- Capacidad de innovación. El tercer lugar invita a la originalidad, a la aventura, al desarrollo de la imaginación, generando una suerte de «ecumenismo social»

- $\quad$ Favorece el debate. Para el autor existen lo que denomina como greater gods, beneficios que auspician el espíritu crítico, la discusión, el debate público y la participación en el mismo.

La aplicación de este modelo a las bibliotecas ha sido objeto de polémica, con miradas encontradas sobre las posibilidades que ofrece (GALLO LEON, 2019), pero es indudable que la aparición de tecnologías de la comunicación que facilitan el intercambio y el flujo de informaciones favorece la generación de espacios en los que la clave no es tanto la existencia de un fondo bibliográfico amplio, sino la de entornos amigables que propicien la conversación sobre ellos $\mathrm{u}$ otros temas y que, indirectamente, estimulen su consumo. El acento se traslada desde lo bibliográfico a lo social, desde lo convencional hacia lo diverso. Se trata de pasar de la lógica de la oferta (la de las instituciones, la de los actores principales de la cadena del libro) a la lógica de la demanda (la de los usuarios) (JACQUET, 2015).

Se está produciendo un cuestionamiento de los modos tradicionales de acceso y difusión del conocimiento, replanteando los modos en que durante siglos se ha accedido a los lugares de custodia del mismo. Frente a la imagen de que este solo operaba sobre una estructura ensimismada y aislada, alejada de los espacios de la vida social, anclada en lugares cerrados y herméticos, se va imponiendo un modelo en que los sistemas de almacenamiento, de mediación, de articulación de los servicios se postula de una manera transparente y abierta, y sobre todo orientada a los usuarios. Las bibliotecas incrementan su función de mediación transformándose en espacios relacionales, donde nazcan nuevas estrategias colaborativas que, indirectamente, beneficien a la sociedad en general. Espacios donde lo físico sigue jugando un papel fundamental (SERVET, 2010). El espacio You Media, de la Biblioteca Municipal de Chicago, o el Espacio 3C de la biblioteca de la Escuela de Tecnología de Montreal, la biblioteca Meriadeck de Burdeos, los laboratorios de la Biblioteca Nacional francesa, donde se experimenta con herramientas digitales relacionadas con la lectura y la escritura, a través de colecciones en la nube, los experimentos como el Book in Room, en los que el holograma de un narrador se relaciona con el público que lo escucha, etc., son algunas de 
las propuestas que intentan dinamizar unos espacios cuyo uso es cada vez más deficiente, y en los que se cuestiona su propia esencia física.

Una de las herramientas con las que contamos para conocer la evolución de la práctica de asistencia a bibliotecas es el informe del Ministerio de Cultura Hábitos y prácticas Culturales de los españoles, en el que se aporta información estadística sobre varias actividades relacionadas con los consumos y hábitos culturales, entre ellas la asistencia a las bibliotecas.

\begin{tabular}{|c|c|c|c|c|c|}
\hline \multicolumn{6}{|c|}{ Encuesta de Hábitos y prácticas culturales: asistencia a bibliotecas } \\
\hline Año & 1 vez año $\%$ & $\begin{array}{c}\text { Acceder } \\
\text { por internet }\end{array}$ & Estudiar & $\begin{array}{c}\text { Buscar } \\
\text { información }\end{array}$ & $\begin{array}{c}\text { Préstamo } \\
\text { libros }\end{array}$ \\
\hline $2002-2003$ & 19,1 & & & & \\
\hline $2006-2007$ & 17,6 & 4,6 & 26 & 31 & 21 \\
\hline $2010-2011$ & 20,5 & 9,6 & 24 & 25 & 21 \\
\hline $2014-2015$ & 22,7 & 7,9 & 20 & 27 & 27 \\
\hline $2018-2019$ & 23 & 9,9 & 30 & 23 & 27 \\
\hline
\end{tabular}

Tabla 1. Datos de asistencia a bibliotecas. Elaboración propia. Fuente: Encuesta de Hábitos y prácticas culturales. Ministerio de Cultura y Deportes

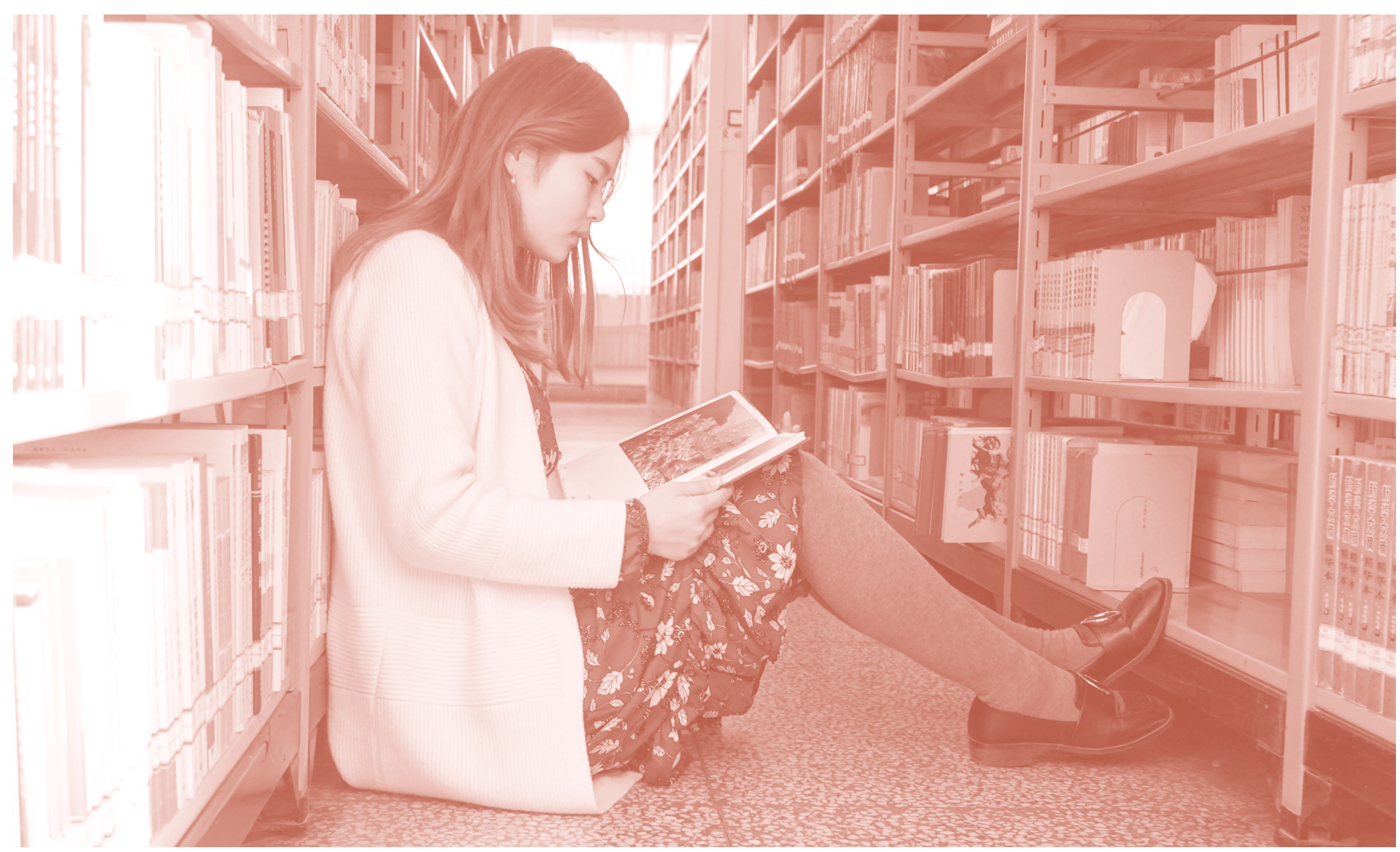


Según los informes publicados, casi un $80 \%$ de la población no va nunca a las bibliotecas, al menos una sola vez al año. Y los que más van lo hacen para estudiar mayoritariamente. Entre la población joven, de los 15 a los 24 años, este era el motivo principal de asistencia (un 60\% responden a este factor como razón principal), mientras que ese mismo sector toma en préstamo libros en unos porcentajes que rondan el 11\%, según el último informe publicado relativo a los años 2018-2019.

La disminución del préstamo de libros en las bibliotecas, la falta de uso y de circulación de estos es una constante de los últimos diez años, no solo en las bibliotecas públicas, sino también en las especializadas. La biblioteca de la Universidad de Yale, por ejemplo, ha disminuido en un $64 \%$ el número de préstamos en los últimos años. La Universidad de Virginia ha pasado de más de 250 mil libros en préstamo durante el año 2008, a 60 mil en la actualidad, en general casi todas las bibliotecas de investigación han comprado el estancamiento de las colecciones físicas de obras en beneficio de las digitales (COHEN, 2019). Podría pensarse que este proceso es, en parte, consecuencia de un notable incremento de la implantación del préstamo digital en las bibliotecas, pero como muestran las estadísticas de uso, el acceso a las mismas desde la red es ínfimo y apenas ha progresado en los últimos años. Aunque los datos del último informe muestran como el acceso a la biblioteca a través de la red se ha duplicado, se partía de unas cifras tan exiguas que los porcentajes relativos no llegan al 10\%, además de que el acceso, del que dan fe las estadísticas, no se convierte automáticamente en préstamo.

Que una obra esté en digital no garantiza su circulación, ni aunque sea de una de las más leídas del mundo. El préstamo digital depende de muchos factores que determinan su mejor o peor funcionamiento. En primer lugar es fundamental la plataforma y las interfaces y prestaciones asociadas a la misma, en segundo lugar que la colección esté debidamente actualizada, en tercer lugar que las obras puedan descargarse con facilidad, en cuarto lugar que la información sobre las mismas y la visibilidad permita a los usuarios estar al tanto de lo que les puede interesar, en quinto lugar el número de licencias debe amortiguar en la medida de lo posible los inconvenientes de la espera en el entorno físico. Ebiblio se lanzó año y medio después de su anuncio y ha funcionado a lo largo de su corta andadura, desde 2015 hasta la actualidad, con dos plataformas diferentes, Libranda primero, y Odilo posteriormente. Todo este conjunto de factores ha provocado que el nivel de préstamos digitales no esté a la al- tura de las previsiones, ni crezca al ritmo que lo hace en otros países. Los informes aportados por eBiblio dan fe de la lenta evolución del préstamo digital, sobre todo en comparación con el préstamo impreso.

En 2015 había 4.098 títulos, de los que se realizaron 246.115 préstamos. El préstamo presencial alcanzó ese año los 33.770.835 préstamos. Es decir, que la división digital represento un $0,56 \%$ del conjunto del préstamo. Si se limita el préstamo únicamente a los libros, el porcentaje llega al 1\%. (EBIBLIO, 2015). Los prestatarios activos (usuarios que han realizado al menos un préstamo en el serivico eBiblio durante el año 2015) eran 48.037.

En 2016 se incrementa el número de títulos disponibles hasta los 8.233, duplicando los existentes el año anterior, aunque no todos los títulos están en todas las redes autonómicas, pero el número de usuarios activos desciende a 45.227. En proporción con el préstamo presencial, el préstamo digital representa el 0,7\% del total de préstamos, y el $1,1 \%$ si se tienen en cuenta únicamente los libros (EBIBLIO, 2016)

En 2017 el número de títulos disponibles asciende a 13.239, esto es, un incremento del 60,8\%, y el número de usuarios se ha estabilizado con tendencia al crecimiento pues alcanza la cifra de 55.625. En este año no se ofrece la proporción del préstamo digital respecto al impreso (EBIBLIO, 2017), pero según el portal de Bibliotecas públicas españolas del Ministerio de Cultura y Deporte se efectuaron 46.970. 367 préstamos, un descenso de más de tres millones respecto al año anterior, de los que el préstamo digital representa el 1\%.

El último informe publicado es el correspondiente al año 2018, en el que la colección de títulos es de 20.092, sumando todos los títulos diferentes con un número de usuarios de 85.227, y un numero de préstamos que, por primera vez supera el millón, ya que asciende a 1.015. 701. Como se dice en el informe el incremento de préstamos se ha visto favorecido por el aumento de títulos disponibles y, especialmente, por la incorporación de publicaciones periódicas (con títulos de revistas en todas las comunidades autónomas y la incorporación de periódicos en algunas de ellas) que presentan unos elevados niveles de préstamo y de rotación por título. Rotación favorecida por tener un periodo de préstamo más reducido (24 horas en la mayoría de los casos). De hecho, las publicaciones periódicas representan el 30\% del total de los préstamos (EBIBLIO, 2018).

La tendencia del préstamo digital, a pesar de todas las dificultades señaladas, es ascendente, frente a un préstamo 
presencial que ha experimentado un fuerte descenso en los últimos años, pasando de 57.066.714 préstamos en el año 2013 a 46.970 .357 en 2017, último año del que se ofrecen datos en el portal de bibliotecas del Ministerio de Cultura. Es decir, que en poco más de cinco años se han perdido más de diez millones de préstamos, en modo alguno compensado por el incremento de la actividad digital. Aunque los usuarios inscritos han crecido en más de un millón entre 2013 y 2017 , así como las colecciones, que han pasado de 82.540.748 títulos en 2013 a 89.234.311 en 2017, las visitas a las bibliotecas públicas han descendido en algo más de cinco millones desde el año 2013.

De cualquier modo, estamos hablando de unas cifras puramente testimoniales que, después de varios años de funcionamiento, no reflejan el potencial que el nuevo sistema entraña. En virtud de todos estos factores se plantea la necesidad de concebir un nuevo modelo de biblioteca y una nueva forma de implicar a los usuarios en el uso de la misma, partiendo de la convicción de que es precisa la imbricación de lo analógico y lo digital, de la biblioteca contemplada como lugar de encuentro presencial y de las posibilidades que ofrece la accesibilidad de la red, para dinamizar y potenciar unos espacios que, hasta ahora, y en gran medida, solo se han aprovechado como meros contenedores de conocimiento. Es así como surge el proyecto de investigación vinculado con la creación de espacios Nubeteca. Nubeteca es la denominación de una nueva concepción de la biblioteca articulada a partir de las experiencias de investigación sobre el entorno de la lectura digital y el libro electrónico desarrollado a iniciativa de la Fundación Germán Sánchez Ruiperez. Las experiencias y conclusiones obtenidas de las investigaciones articuladas en torno a Territorio ebook (CORDON GARCÍA, 2016), facilitaron la elaboración teórica de un nuevo concepto de biblioteca pública (VALBUENA Y CORDÓN, 2014), bajo la denominación de Nubeteca que, se concretó en las iniciativas puestas en marcha por la Diputación de Badajoz para sus bibliotecas, en las que la propuesta se ha ido haciendo realidad en estos últimos años (https://dipbadajoz.odilotk.es/ opac/\#indice).

\section{El proyecto de investigación Nubeteca}

A partir de todos los antecedentes mencionados y como parte del proyecto europeo 1234redes.com, auspiciado por la Unión Europea, la Diputación de Badajoz y la Fundación Germán Sánchez Ruipérez ponen en marcha el proyecto "Análisis del impacto de los espacios Nubeteca en el préstamo digital", cuyo desarrollo queda a cargo de investigadores de la Universidad de Extremadura y del grupo E-lectra la Universidad de Salamanca, en colaboración con ambas instituciones. El proyecto se sustenta en la fundación de veinte "Puntos Nubeteca", esto es, espacios nuevos dedicados a la dinamización de las colecciones digitales, dentro de determinadas bibliotecas, de la provincia de Badajoz. El proyecto se desarrolla desde abril de 2018 a diciembre de 2019, aunque los análisis y conclusiones se extienden hasta 2020.

Los objetivos de la investigación son:

- Analizar de manera comparada la evolución del préstamo digital en las principales redes de bibliotecas públicas en España y análisis de las causas que permiten acelerar su desarrollo o frenar su implantación.

- Identificar las principales estrategias de difusión del servicio de préstamo digital en dichas redes bibliotecarias: digitales: web, news, redes sociales, y físicas: carteles, trípticos, información verbal, en las bibliotecas que participarán en la investigación.

- $\quad$ Profundizar en el papel que juega en ese proceso la conformación de los espacios físicos de la biblioteca en relación con otras variables como las características de la colección disponible, la usabilidad de la plataforma, o la tipología de usuarios activos de la biblioteca.

- Medir el impacto de las siguientes acciones:

- Visibilidad del catálogo digital en el espacio físico

- Formación de lectores y bibliotecarios

- Dinamización del espacio

Y determinar si se ha conseguido:

- Aumentar el préstamo digital

- Mejorar la tasa de conversión de lectores analógicos a digitales

- Fomentar la participación de los usuarios en clubes de lectura digital

- Definir las características y el diseño del espacio

- Modelizar la formación de lectores competentes digitalmente

\section{Metodología desarrollada}

El proyecto pretende determinar cómo afectan a la lectura digital (y al fomento de esta) los cambios en el espacio físico en las bibliotecas. Para ello, como se ha indicado anteriormente, se ha implementado un espacio Nubeteca en un 
grupo de bibliotecas (veinte), manteniendo un grupo de con- $\quad$ resultados de las bibliotecas que no contaban con un espacio trol sin dicho espacio para, posteriormente, poder analizar el impacto que este ha podido tener relacionándolo con los $\quad y$ consumo de libros digitales.

Población

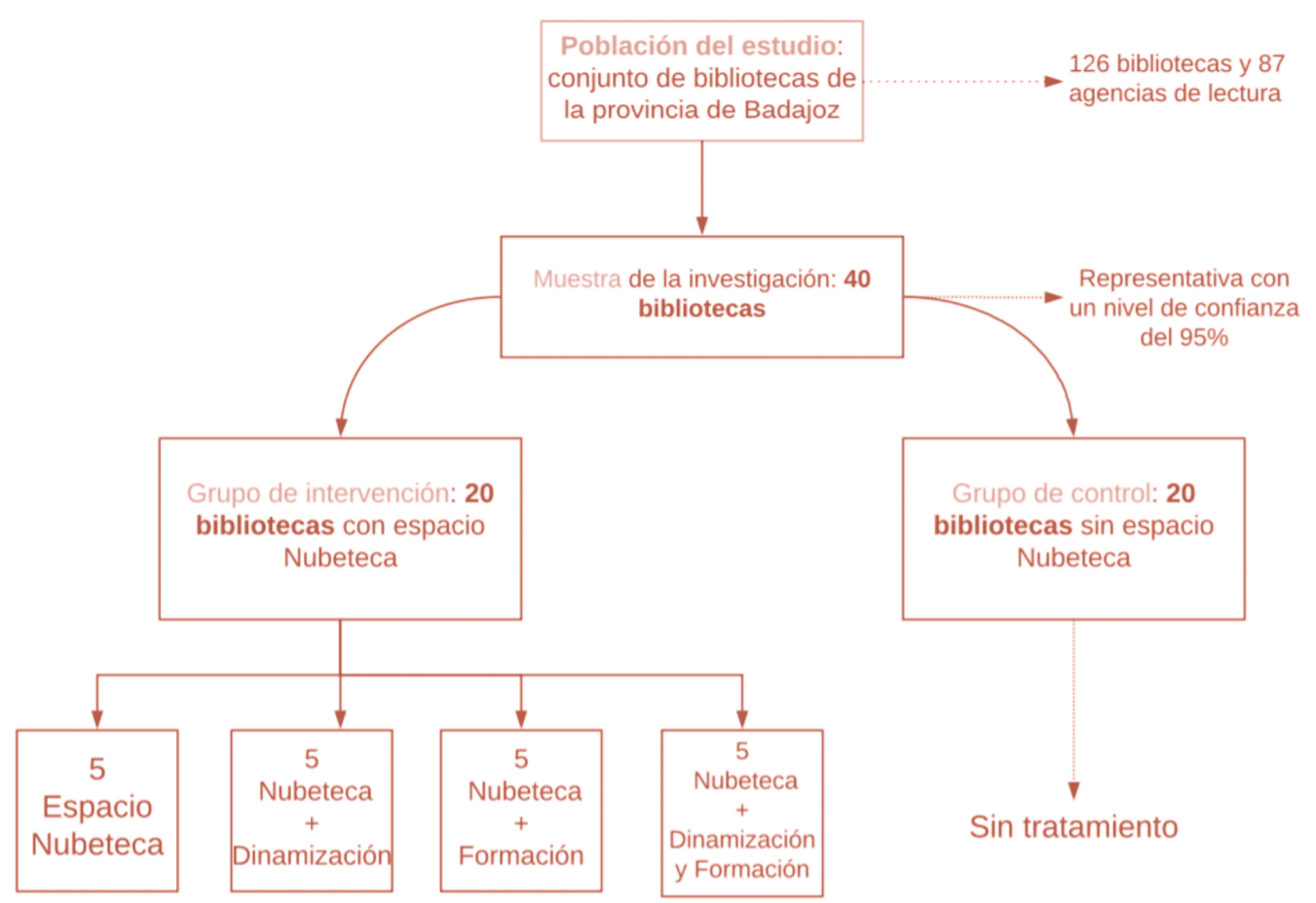

Fig. 1. Esquema de investigación proyecto Nubeteca

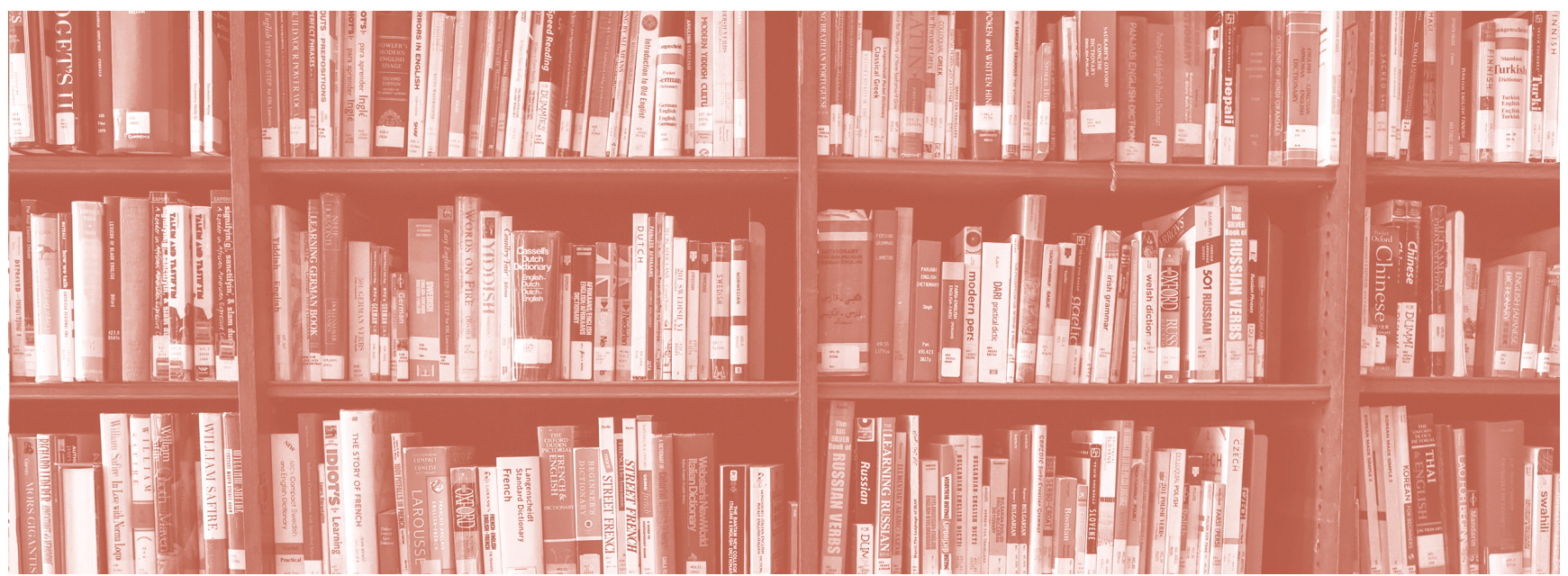


El desarrollo del proyecto incluye la gestión y análisis de datos de distinta naturaleza: datos cuantitativos referentes a la caracterización de la población estudiada, a las características socioeconómicas en las que se incluyen las unidades de observación, relacionados con las infraestructuras de los centros de observación (bibliotecas), con las colecciones impresas y digitales que gestionan los centros de observación. Los servicios que ofrece cada institución, con el uso, préstamo y consumo en las colecciones, con los proyectos y programas de difusión de las colecciones, con las actividades sociales y culturales puestas en marcha en cada centro de observación

Los espacios Nubeteca se contemplan como unidades integradas plenamente en las bibliotecas, en lugares claramente identificables por los usuarios, en los que se ofrecen un conjunto de servicios relacionados con las colecciones digitales de la biblioteca y con las prestaciones asociadas a las mismas.

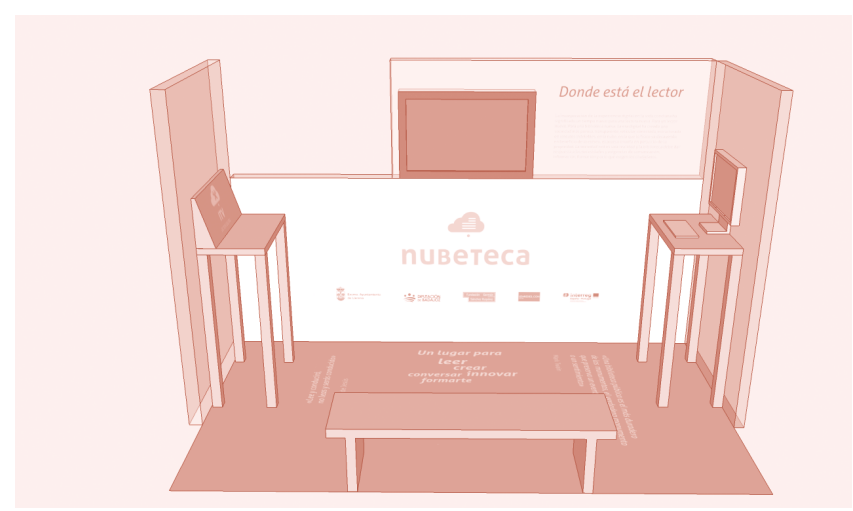

Arquitectura Espacio Nubeteca

Cada espacio Nubeteca está equipado con un monitor Smart TV DE 42 pulgadas, dos Ipad y un ordenador de sobremesa.

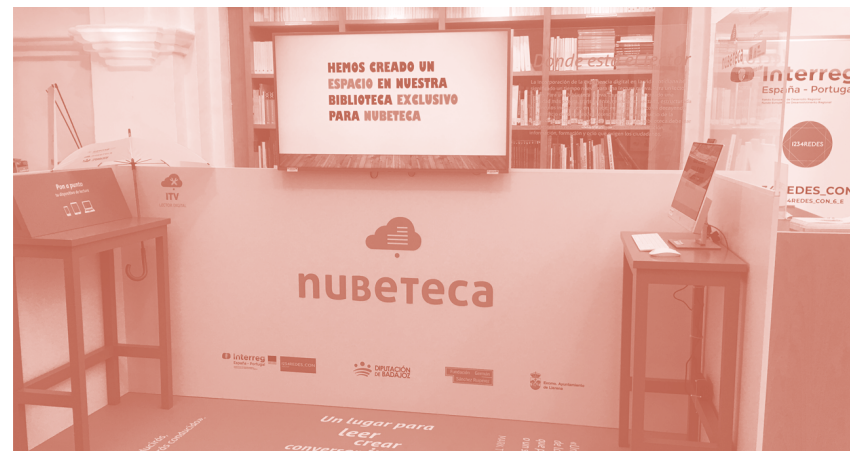

Espacio Nubeteca. Biblioteca de Llerena (Badajoz)
Son espacios contemplados para el desarrollo de un conjunto de acciones de diferente naturaleza, centradas en la formación, la recomendación, la promoción de la lectura y la dinamización de la colección digital. Sus cometidos serían:

- Formación. ITV digital: realizada entre bibliotecarios y lectores o también entre pares

- Configurar los dispositivos

- Acceder al catálogo digital

- Realizar un préstamo

- Recomendación de lecturas

- A través del monitor presente en el espacio Nubeteca

- y de otros dispositivos: ordenador de sobremesa y tableta

- Consultar del catálogo a través a través de los dispositivos electrónicos existentes en el espacio Nubeteca: ordenador, tableta y códigos QR

- Realización de préstamos a través de los dispositivos electrónicos: ordenador, tableta y códigos QR

- Promoción y gestión de los Clubes de Lectura Nubetecos

- $\quad$ Presentaciones de libros u otros eventos de la biblioteca

- Fijación de marca en torno a la oferta digital de la biblioteca

Dentro del proyecto la implantación de estos espacios se incluye igualmente un proceso de dinamización de los mismos a través de un conjunto de acciones que persiguen la potenciación de la biblioteca como lugar de conversaciones y encuentro, en combinación con la colección digital. Esta actividad de dinamización entraña la articulación de acciones de muy diversa naturaleza, emprendidas en cada una de las bibliotecas seleccionadas, cuyos efectos se contrastarán con aquellas bibliotecas que no han recibido dinamización alguna. Las acciones desarrolladas comprenden cuatro líneas de trabajo:

- Difusión del proyecto Nubeteca en las Bibliotecas Municipales participante en la primera fase del proyecto (Creación de un espacio en http://www.nubeteca.info/minisite/index.html, inclusión en la web de una galería de imágenes de Nubeteca, elaboración de una guía del espacio Nubeteca (Nubeguía), diseño de letreros para colocarlos en lugares estratégicos del municipio y en los muros exteriores de las 
bibliotecas, elaboración de una infografia, difusión de las actividades y el proyecto a través de la redes sociales, visitas personales a colegios, institutos, centros sociales, etc., instalación de tabletas en la pared del espacio Nubeteca.

- Conocimiento y difusión de la colección digital, que en la actualidad supera los veinte mil títulos, y de las plataformas de libros digitales. Creación de tarjetas de estante (shelf peeker) con un número de títulos seleccionados tanto de adultos como de infantil (cincuenta títulos en total, diseño de pegatinas con el logo Nubeteca y la frase «también en digital»). Colocación de carteles en forma de tableta con portadas de libros electrónicos en la sección de las novedades de los libros en papel.

- Fomento del préstamo de libro digitales por parte de los usuarios de las bibliotecas participantes (elaboración de carruseles temáticos, conmemorativos, etc.). Dinamización de audiolibros de la plataforma «El libro digital de la semana», los usuarios/bibliotecarios recomiendan.

- Formación de bibliotecarios y usuarios (tutoriales del uso de la plataforma y la aplícación en la web Nubeteca, inclusión de un apartado de preguntas frecuentes. Te ayudamos, sobre el espacio, cómo descargar la $a p p$, cómo utilizar determinado dispositivo, cómo buscar un libro. Talleres específicos para cada dispositivo (ordenador, tabletas y móviles). Taller de presentación del espacio Nubeteca, de la plataforma y cómo se hace el préstamo, Diseño de recompensas para los usuarios que hagan préstamo digital, estrategias de gamificación con el préstamo digital.

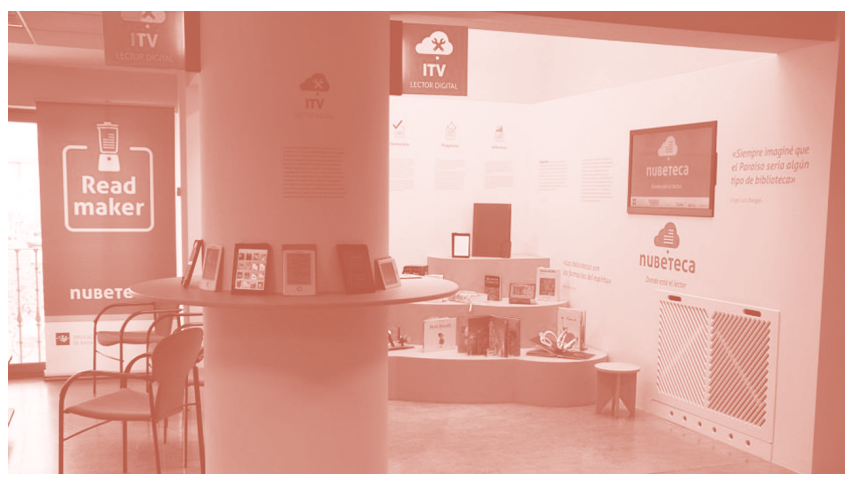

Espacio Nubeteca de la Fundación Germán Sánchez Ruipérez (Peñaranda de Bracamonte, Salamanca)
El proceso de recogida de datos se estructura en torno a un programa de carácter diacrónico que contempla el registro de información a lo largo del periodo que dura el estudio.

El estudio parte con una primera toma de datos pretratamiento inicial que tendrá como objetivo caracterizar el estado de las unidades de observación en relación con el uso y acceso de la colección digital, además de observar el comportamiento general tanto del centro como de los usuarios en relación con las ratios de préstamo, labores de dinamización, actividades culturales, etcétera.

En una segunda fase, se realizará una nueva toma de datos, que tiene como finalidad principal observar los eventuales cambios de comportamiento en el lector digital que implican las medidas adoptadas dentro del conjunto del tratamiento de la variable:

- disposición del espacio en la biblioteca,

- implementación de actividades de dinamización

- desarrollo del programa de formación

Decía Umberto Eco, en un conocido opúsculo de significativo título «De Bbilioteca» (EGO, 2008) «pero la función principal de la biblioteca... es la de descubrir libros cuya existencia no se sospechaba y que, sin embargo, revelan ser de extrema importancia para nosotros». La finalidad del proyecto es precisamente esa, descubrir al lector una realidad nueva, la de la biblioteca contemplada desde una óptica integradora, en la que lo físico no se concibe sin lo digital y viceversa. Pero también un espacio de encuentro, de conversación y de descubrimiento, de lecturas y de experiencias. Estamos convencidos de que la función de la biblioteca debe de ir acompasada a los tiempos, y de que en la actualidad esta acomodación es imprescindible si no se quiere convertir estos lugares en meros parques temáticos o museos más próximos a la arqueología industrial (o bibliográfica) que a sitios de dinamización cultural y creación comunitaria.

\section{Bibliografía}

COHEN, D. (2019): "The Books of College Libraries Are Turning Into Wallpaper" en The Atlantic, págs. 18-19.

CORDÓN GARCÍA, J. A. (2016): "La lectura digital y la formación del lector digital en España: la actividad de la Fundación Germán Sánchez Ruipérez y el Proyecto Territorio Ebook" en Alabe, n 13, págs. 207-233. 
DARNTON, R. (2010): Las razones del libro: futuro, presente y pasado, Madrid, Trama editorial.

EBIBLIO (2015, 2016, 2017, 2018): Informe de actividad, Madrid, Ministerio de Cultura y Deporte.

ECO, U. (2008): De biblioteca, Almería, Ediciones Perdidas, pág. 27

GALLO-LEÓN, J. P. (2019): “Crítica y ratificación del modelo de tercer lugar para las bibliotecas" en Anuario ThinkEPI, v. 13, e13b01.

JACQUET A. (2015): Bibliothèques troisième lieu, París, Association des Bibliothécaires de France, págs. 32-42.

MUÑOZ MOLINA, A. (2019): "En la vida real", El País, 28 de septiembre de 2019.
MURRAY, S.: Bibliotecas (Historia), Madrid, La Esfera de los libros.

OLDENBURG, R. (1999): The Great Good Place: Cafes, Coffee Shops, Bookstores, Bars, Hair Salons, and Other Hangouts at the Heart of a Community: Cafaes, Coffee Shops, ... Other Hangouts at the Heart of a Community, Da Capo Press edition, págs. 88-94.

SERVET, M. (2010): "Les bibliothèques troisième lieu: Une nouvelle génération d'établissements culturels" en Bulletin des Bibliotheques de France, $\mathrm{n}^{\circ} 4$.

VALBUENA RODRÍGUEZ, J. y CORDÓN GARCÍA, J. A. (2014): Nubeteca: la biblioteca pública del presente, Madrid, Lectyo. 